\title{
Modeling and simulation of Triclosan kinetics and distribution in humans using a PBPK model
}

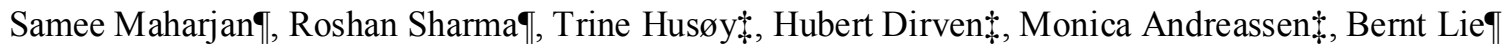 \\ II Telemark University College, Norway \\ $\ddagger$ Dept. of Food, Water and Cosmetics; Norwegian Institute of Public Health (NIPH)
}

\begin{abstract}
Triclosan is an antibacterial additive which is widely used in personal care products (PCPs) such as soaps, perfumes etc. Previous studies have indicated that triclosan might have potential to adverse effects on the human health. Some traces of triclosan are found in human plasma and milk at a concentration which is likely to be related to the use of PCPs.

In this study, a Physiologically Based Pharmacokinetic or Toxicokinetic (PBPK/TK) model is developed to assess the concentration of triclosan in human organs after exposure through the skin (dermal) or the oral canal. The absorbed chemical is metabolized in the liver and leaves as conjugates and then excreted through kidney in the urine. The simulation is done using MATLAB. Lastly, the developed model is fitted using least square techniques in MATLAB using synthetic data generated from the model itself with or without the addition of random noise.
\end{abstract}

\section{Keywords: Triclosan, PBPK, Model fitting}

\section{Introduction}

The excess use of chemicals in PCPs, it has attracted concern from pharmacists, chemists and environmentalists. Human exposure to common household chemicals is a potential health risk. Triclosan is one of these chemicals which are widely used as an antibacterial compound in cosmetic products. Triclosan is an off white chlorinated aromatic compound, which consists of two benzene rings linked by an oxygen atom, with three chlorine atoms and a hydroxyl group attached. It was first used in 1970s in hospitals since then become a widely used anti bacterial agent. While people who use triclosan products daily have higher levels of the chemical in their bodies, even consumers who do not use triclosan on their skin are exposed to it through food, water, and even household dust ${ }^{1}$.

Physiologically Based Pharmacokinetic /Toxicokinetic (PBPK/TK) Models are commonly used in the pharmaceutical and toxicological sciences to understand the distribution of chemicals in the human body. Mathematically based differential equations are used to depict pharmacokinetic processes in terms of physiological and biochemical parameters. PBPK/TK

\footnotetext{
${ }^{1}$ www. newsweek.com

${ }^{2}$ Outermost layer of skin.
}

modeling can be taken as an example of using simple modeling technique for model development and then simulate accordingly. These models are widely used in the field of toxicology and risk assessment. In (Mielke \& Gundert-Remy, 2012), three different case studies for two chemicals are presented. One case study is done for the effect of Bisphenol A on the newly born child, whereas other two are the assessing the concentration of Bisphenol A and Coumarin in the body organs through dermal penetration. For all three case studies a PBTK model is used with required physiological and chemical parameters. Basically these models described the distribution of a chemical, in the human organs according to its absorption, metabolism and excretion. The results from such simulations are basically the chemical concentrations that will eventually stay in the body after exposure and distribution to target organs for toxicity. A PBPK/TK model comprises the physiology of the body and the toxicokinetic properties of the chemical. It is not possible to determine the risk of the chemical based on the modeling. To do that we need real exposure data and compare this with the toxicity of the compound. If the human exposure are low, the risk is also low, independent of the knowledge of the distribution at a certain dose.

In this paper, we develop a PBPK/TK model for assessing the distribution of triclosan in the human organs after exposure through both the oral and the dermal route. In Section 2, a description of the system under study is given. In section 3, a detail of model development using species balance for each organ is shown. All the simulation results are given in Section 4 whereas sensitivity analysis and model fitting for uncertain parameters are discussed in Section 5. Lastly the results of the paper are discussed in section 6 .

\section{System Description}

Studies show that after almost 2 hours of dermal application in rats, traces of triclosan are seen in the blood system. By 24 hours, $23 \%$ of the applied dose appeared in blood whereas remaining dose is resided in the skin. Metabolism of triclosan mainly takes place in the liver but a small amount is also metabolized in the skin itself. The percentage of glucuronide are found to be higher than that of sulfate $(4.1 \%$ vs. $0.9 \%$ at 24 hrs) in blood, this suggests that most of the formed sulfate remains in skin but glucuronide diffuse more 
readily into blood by virtue of hydrophilicity. Absorption of triclosan in the human skin is approximately 5 times slower than in the rats. This is because rats possess thinner stratum corneum ${ }^{2}$ and larger number of hair follicles than humans (Moss, Howes, \& Williams, 2000) . For oral application, the triclosan dose is directly transported to the liver where metabolism takes place before entering the systemic circulation through first pass metabolism. Thus, the amount of free triclosan found in blood after oral exposure is less than the amount after dermal application for the same dose. The ratio between the two conjugates varies from species to species. Different studies show that for humans, almost all the applied dose is converted into conjugates with approximately $90 \%$ as glucuronides and $10 \%$ as sulfates. In contrast, 78-90\% of the triclosan was found as sulfate conjugates in mice (Rodricks, Swenberg, Borzelleca, Maronpot, \& Shipp, 2010). Triclosan excreted predominantly as its conjugates. Irrespective to the route of application, the major route of elimination in humans is through urine while in rats triclosan is excreted in faeces. Triclosan in rat will therefore undergo entherohepatic circulation ${ }^{3}$. In the intestine of rats the conjugated triclosan is deconjugated by glucuronidases and sulphatases, and the free triclosan is re-absorbed (Moss et al., 2000).

\section{Metabolism of Triclosan}

The main metabolites of triclosan are the conjugation products triclosan sulfate and triclosan glucuronide Figure 1. The conjugation of triclosan is described as follows. A family of enzymes known as SULT (sulfotransferase) catalyze the transfer of a sulfonate group (-SO-3) from PAPS (3'phosphoadenosine-5'-phosphosulfate) to triclosan, forming the conjugate triclosan sulfate with the release of PAP (3-phosphoadenosine-5-phosphate). Denoting triclosan by $\mathrm{T}$ and triclosan sulfate by TS, we can write the overall reaction as,

$$
\text { PAPS }+\mathrm{T} \stackrel{\text { SULT }}{\longrightarrow} \mathrm{T}_{\mathrm{S}}+\text { PAP. }
$$

\footnotetext{
${ }^{2}$ Outermost layer of skin.

${ }^{3}$ the circulation of substances from the liver to the bile, followed by entry into the small intestine, absorption by the enterocyte and transport back to the liver.
}

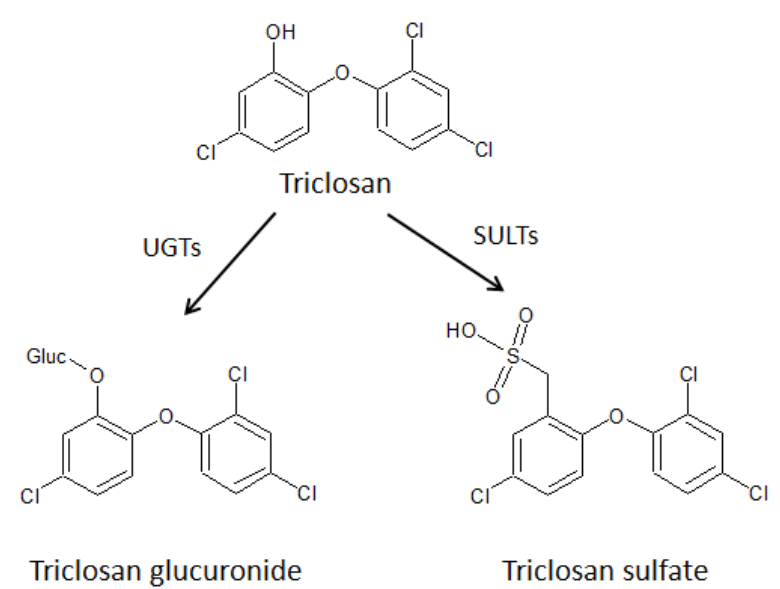

Figure 1: Metabolism of triclosan into glucuronides
and sulfates (After Fang et al., 2010).

Similarly, an enzyme known as UGT (Uridine 5'diphospho-glucuronosyl transferase $=$ UDPglucuronosyl transferase) catalyzes the transfer of the glucuronic acid component of UDP-glucuronic acid to triclosan, forming the conjugate triclosan glucuronide as well as a residual of UDP-glucuronic acid. Denoting UDP-glucuronic acid by $\mathrm{G}$, the conjugate triclosan glucuronide by $\mathrm{T}_{\mathrm{G}}$, and the residual of UDP-glucuronic acid by $\bar{G}$, we can write the overall reaction as,

$$
\mathrm{G}+\mathrm{T} \stackrel{\mathrm{UGT}}{\longrightarrow} \mathrm{T}_{\mathrm{G}}+\mathrm{G} \text {. }
$$

In both cases, triclosan (T, substrate) is absorbed on the enzyme surface and is inserted into the active site. Provided that triclosan has been absorbed into the active site, we assume that a co-substrate $\left(\mathrm{PAP}_{\mathrm{S}}\right.$ or $\left.\mathrm{G}\right)$ also is adsorbed at the active site, forming a substrate/co-substrate complex. Next, a reaction takes place in this complex formed at the active site, and conjugated triclosan $\left(T_{S}\right.$ or $\left.T_{G}\right)$ is formed together with a co-product (PAP or $\overline{\mathrm{G}}$ ) and these then desorbs from the active site. Under the conditions of constant enzyme concentration and constant co- factor concentration, the overall reaction rate referring to triclosan can be written as,

$$
\hat{\mathrm{r}}_{\mathrm{j}}=\hat{\mathrm{r}}_{\max } \frac{\mathrm{c}_{\mathrm{T}}}{\mathrm{c}_{\mathrm{T}}+\mathrm{K}_{\mathrm{T}, \mathrm{j}}},
$$

where $\left[\hat{r}_{j}\right]$ is given in mole/(time and protein mass), and $\mathrm{j} \in\{\mathrm{S}, \mathrm{G}\}$. The individual reaction rates are thus:

$$
\begin{aligned}
\hat{r}_{\mathrm{S}} & =\hat{\mathrm{r}}_{\max , \mathrm{S}} \frac{\mathrm{c}_{\mathrm{T}}}{\mathrm{c}_{\mathrm{T}}+\mathrm{K}_{\mathrm{T}, \mathrm{S}}} \\
\hat{\mathrm{r}}_{\mathrm{G}} & =\hat{\mathrm{r}}_{\max , \mathrm{G}} \frac{\mathrm{c}_{\mathrm{T}}}{\mathrm{c}_{\mathrm{T}}+\mathrm{K}_{\mathrm{T}, \mathrm{G}}}
\end{aligned}
$$

In (Wang, Falany, \& James, 2004), the rate constants are given for human liver as From Table 1 it should be observed that the molar rates of generation are given as

$$
\dot{\mathrm{n}}_{\mathrm{j}}^{\mathrm{g}}=\hat{\mathrm{r}}_{\mathrm{j}} \cdot \mathrm{m}_{\mathrm{P}, \mathrm{j}},
$$

where $m_{P, j}$ is the relevant mass of protein in the liver. Sulfonation takes place in the human liver cytosol while glucuronidation takes place in the liver 
microsomes. Due to the fact that sulfatation occurs in cytosol and glucuronidation occurs in membranes of the liver, the protein mass for the two enzymes would differ (Wang et al., 2004). These protein masses is needed because the $\hat{r}_{\max }$ and $\mathrm{K}_{\mathrm{T}}$ is taken from human in vitro liver studies. If we had data from formation of conjugates in human blood, we would not need these factors.

Ideally, we would like to relate $m_{P, j}$ to the mass $\mathrm{m}_{\mathrm{h}}$ of the liver as an organ instead (hepatic mass), in other words to $\xi_{\mathrm{j}}$ satisfying

$$
\mathrm{m}_{\mathrm{P}, \mathrm{j}}=\xi_{\mathrm{j}} \mathrm{m}_{\mathrm{h}} \text {. }
$$

In (Cubitt, Houston, \& Galetin, 2009), the hepatic cytosolic scaling factor was found in the range $\xi_{\mathrm{h}, \mathrm{s}} \in$ $\{45,134\} \mathrm{mg}$ protein in liver cytosol per $\mathrm{g}$ of liver, with a mean weighted value $\xi_{\mathrm{h}, \mathrm{s}}=80.7 \times 10-3$. They also report a typical fraction protein in intestine cytosol per $\mathrm{g}$ intestine to be $\xi_{\mathrm{i}, \mathrm{s}}=18 \times 10-3$. It should be observed that the rate numbers given in Table 1 do not necessarily carry over from liver to intestine. In (Barter et al., 2007), experimental results are cited in the range $\xi_{\mathrm{h}, \mathrm{G}} \in\{19,77\} \mathrm{mg}$ protein in livermicrosomes per $\mathrm{g}$ of liver. The value probably varies among individuals, with age, and by gender. A possible useful value may be $\xi_{\mathrm{h}, \mathrm{G}}=30 \times 10-3$. In (Johnson, Tucker, Tanner, \& Rostami-Hodjegan, 2005) variation in liver size $\left(m_{h}\right)$ for humans is discussed.

Table 1: Michaelis-Menten reaction parameters for triclosan metabolism in human liver (Wang et al., 2004).

\begin{tabular}{|l|l|l|}
\hline & $\mathrm{K}_{\mathrm{T}, \mathrm{j}, \mathrm{li}}\left[\frac{\mu \mathrm{mol}}{\mathrm{L}}\right]$ & $\hat{\mathrm{r}}_{\text {max,j,li }}\left[\frac{\text { pmol }}{\min \text { mg protein }}\right]$ \\
\hline Sulfonation (S) & $8.5 \pm 3.2$ & $95.1 \pm 28.4$ \\
\hline $\begin{array}{l}\text { Glucuronidation } \\
(\mathrm{G})\end{array}$ & $107 \pm 2.2$ & $739 \pm 163$ \\
\hline
\end{tabular}

\section{Model development}

Figure 2 illustrates the topology of a network of organs describing the transport of chemicals from its absorption through the skin and/or the GI tract to its excretion through the kidney. After absorbing chemical through the skin, triclosan along with its conjugates passes through the skin and mix with the central blood system.

The central blood system then transports these chemicals into almost every organ. The circulation process continues until the entire dose intake has been eliminated. The excretion of chemical is via the kidney through urine. Triclosan is relative hydrophilic and does not accumulate in the body and is rapidly metabolized and excreted. Thus we can assume that the membrane between tissue and capillary of an organ is of no barrier. For this kind of chemicals, their kinetics can be best described by a perfusion-rate-limited kinetics. A single compartmental model is used for model development process.

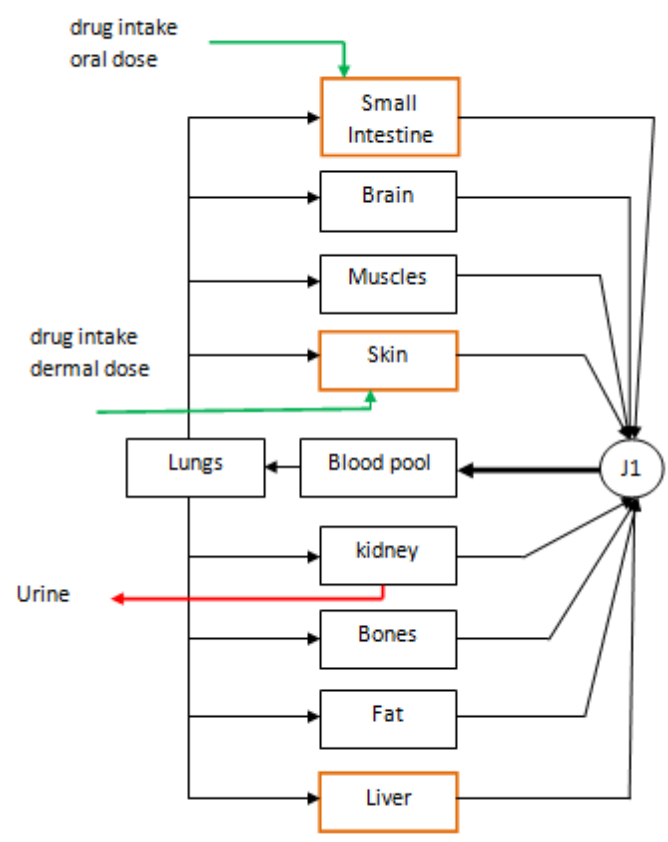

Figure 2: Flow of chemical intake (Beard, 2012).

\section{Species Balance}

The general species balance in molar form,

$$
\frac{d n_{j}}{d t}=\dot{n}_{j}^{i}-\dot{n}_{j}^{e}+\dot{n}_{j}^{g} \text {. }
$$

Here,

$\dot{\mathrm{n}}_{\mathrm{j}}^{\mathrm{g}}=$ Number of moles generated of species $\mathrm{j}$.

$\dot{\mathrm{n}}_{\mathrm{j}}^{\mathrm{i}}=$ Influx number of moles per unit time of species $\mathrm{j}$.

$\dot{\mathrm{n}}_{\mathrm{T}}^{\mathrm{e}}=$ Efflux number of moles per unit time of species $\mathrm{j}$.

\section{For non metabolic organs}

The number of moles expressed in the form of concentration as,

$$
\begin{aligned}
\dot{\mathrm{n}}_{\mathrm{j}}^{\mathrm{i}} & =\dot{\mathrm{V}} \mathrm{c}_{\mathrm{j}}^{\mathrm{i}} \\
\dot{\mathrm{n}}_{\mathrm{j}}^{\mathrm{e}} & =\dot{\mathrm{V}} \mathrm{c}_{\mathrm{j}}^{*} .
\end{aligned}
$$

Here $c_{j}^{*}=\frac{c_{j}}{\lambda}, \lambda$ is the partition coefficient and as there will be no any chemical reformation,

$$
\dot{\mathrm{n}}_{\mathrm{j}}^{\mathrm{g}}=0
$$

thus the reaction can be described by the equation,

$$
\frac{\mathrm{dn}_{\mathrm{j}}}{\mathrm{dt}}==\dot{\mathrm{V}}\left(\mathrm{c}_{\mathrm{j}}^{\mathrm{i}}-\mathrm{c}_{\mathrm{j}}^{*}\right) \text {. }
$$

Here $\mathrm{j}=\left\{\right.$ free triclosan $(\mathrm{T})$, triclosan sulfate $\left(\mathrm{T}_{\mathrm{S}}\right)$, triclosan glucuronide $\left.\left(\mathrm{T}_{\mathrm{G}}\right)\right\}$. 


\section{For metabolic organs}

For the liver and the skin where there is breakdown of free triclosan into its conjugates, the reactions can be represented by,

$$
\begin{gathered}
\frac{\mathrm{dn}_{\mathrm{T}, \mathrm{k}}}{\mathrm{dt}}=\dot{\mathrm{V}}\left(\mathrm{c}_{\mathrm{T}, \mathrm{k}}^{\mathrm{i}}-\mathrm{c}_{\mathrm{T}, \mathrm{k}}^{*}\right)-\dot{\mathrm{n}}_{\mathrm{T}, \mathrm{k}}^{\mathrm{g}}+\dot{\mathrm{n}}_{\mathrm{d} 2 \mathrm{~s}} \\
\frac{\mathrm{dn}_{\mathrm{T}_{\mathrm{G}, \mathrm{k}}}}{\mathrm{dt}}=\dot{\mathrm{V}}\left(\mathrm{c}_{\mathrm{T}_{\mathrm{G}, \mathrm{k}}}^{\mathrm{i}}-\mathrm{c}_{\mathrm{T}_{\mathrm{G}, \mathrm{k}}}^{*}\right)+\dot{\mathrm{n}}_{\mathrm{T}_{\mathrm{G}, \mathrm{k}}}^{\mathrm{g}} \\
\frac{\mathrm{dn}_{\mathrm{T}_{\mathrm{S}, \mathrm{k}}}}{\mathrm{dt}}=\dot{\mathrm{V}}\left(\mathrm{c}_{\mathrm{T}_{\mathrm{S}, \mathrm{k}}}^{\mathrm{i}}-\mathrm{c}_{\mathrm{T}_{\mathrm{S}, \mathrm{k}}}^{*}\right)+\dot{\mathrm{n}}_{\mathrm{T}_{\mathrm{S}, \mathrm{k}}}^{\mathrm{g}}
\end{gathered}
$$

Here ' $k$ ' is for the liver and the skin. $\dot{n}_{\mathrm{d} 2 \mathrm{~s}}$ is the amount of chemical applied either through the skin or the mouth.

The excretion is through the kidney as urine.

$$
\dot{\mathrm{n}}_{\mathrm{j}, \mathrm{k} 2 \mathrm{u}}=\theta_{\mathrm{k} 2 \mathrm{u}} \mathrm{c}_{\mathrm{j}, \mathrm{ins}}^{*}
$$

\section{Flow Junction}

The flow topology has one junction at the inlet to the blood pool. For this junction, no matter is accumulated. Steady state species balances for this junction lead to:

$$
\begin{aligned}
\dot{\mathrm{n}}_{\mathrm{k}, \mathrm{bp}}^{\mathrm{e}}=\dot{\mathrm{n}}_{\mathrm{k}, \mathrm{ins}}^{\mathrm{e}}+ & \dot{\mathrm{n}}_{\mathrm{k}, \mathrm{br}}^{\mathrm{e}}+\dot{\mathrm{n}}_{\mathrm{k}, \mathrm{mu}}^{\mathrm{e}}+\dot{\mathrm{n}}_{\mathrm{k}, \mathrm{sk}}^{\mathrm{e}}+\dot{\mathrm{n}}_{\mathrm{k}, \mathrm{ki}}^{\mathrm{e}}+\dot{\mathrm{n}}_{\mathrm{k}, \mathrm{bo}}^{\mathrm{e}} \\
& \dot{\mathrm{n}}_{\mathrm{k}, \mathrm{fa}}^{\mathrm{e}}+\dot{\mathrm{n}}_{\mathrm{k}, \mathrm{li}}^{\mathrm{e}} \\
& \dot{\mathrm{n}}_{\mathrm{k}, \mathrm{b} p}^{\mathrm{e}}=\dot{\mathrm{n}}_{\mathrm{k}, \mathrm{lu}}^{\mathrm{i}}
\end{aligned}
$$

Here subscript "k" denotes the possible substrate i.e. free triclosan, glucuronide and sulfate.

\section{Simulation and Analysis}

\section{Model parameter}

Table 2 shows the standard model parameters used for PBPK model development for human. All the standard parameters are extracted from (Mielke et al., 2011). Additional parameters that are used in implementing metabolism and excretion of triclosan in human body are given in Table 1 . So far no specific data for skin is provided, thus $20 \%$ of corresponding parameter of liver is used for reaction kinetics in the Skin. The chemical excretion coefficient from kidney to urine is estimated from the standard chemical excretion coefficient of rats by using the tissue volume ratio for scaling.

Tissue volume of kidney for rats $=2.77 \mathrm{ml}$

Tissue volume of kidney for humans $=310 \mathrm{ml}$

$\theta_{\mathrm{k} 2 \mathrm{u}}$ for rats $=0.490 \mathrm{ml} / \mathrm{s}($ Beard, 2012)

$\theta_{\mathrm{k} 2 \mathrm{u}}$ for human $=0.490 * 310 / 2.77=54.8 \mathrm{ml} / \mathrm{s}$

Effective permeation for the conjugates is different from their parent chemical. As there is lack of the exact value for the effective permeation of triclosan conjugates, a chemical excretion coefficient of parent compound which is scaled by 4 is used.
Table 2: Standard parameters for human (Mielke et al., 2011) .

\begin{tabular}{|l|l|l|l|l|}
\hline \multicolumn{2}{|l|}{ Organ } & $\begin{array}{l}\text { Volume } \\
\text { of tissue } \\
\text { Vt [ L] }\end{array}$ & $\begin{array}{l}\text { Flowrate } \\
{[\mathrm{L} / \mathrm{hr}]}\end{array}$ & $\begin{array}{l}\text { Partition } \\
\text { Coefficient } \\
{[\lambda][-]}\end{array}$ \\
\hline No. & Name & & & \\
\hline 1 & Brain & 1.45 & 46.8 & 0.73 \\
\hline 2 & Muscle & 29.2 & 65.8 & 0.29 \\
\hline 3 & Bone & 9.33 & 7.8 & 0.23 \\
\hline 4 & Fat & 18.2 & 19.5 & 4.20 \\
\hline 5 & Skin & 2.7 & 20 & 0.77 \\
\hline 6 & Kidney & 0.31 & 74.1 & 0.51 \\
\hline 7 & $\begin{array}{l}\text { Small } \\
\text { Intestine }\end{array}$ & 3.7 & 20 & 0.57 \\
\hline 8 & Liver & 1.8 & 99.5 & 0.57 \\
\hline 9 & Lung & 1.432 & 353.5 & 1.16 \\
\hline 10 & Blood pool & 5 & 353.5 & - \\
\hline
\end{tabular}

\section{Operating condition}

The following operating conditions are used in the model:

- Initial states: all are zero.

- Body weight (bw):73 kg

- Chemical dose $0.1 \mathrm{~g} / \mathrm{kg}$ bw is supplied continuously for 2 hours.

\section{Simulation results}

The simulations are carried out using MATLAB for both oral and dermal application. The level of concentration in the simulation is presented as the number of accumulated moles of chemicals $\left(T, T_{S}\right.$ and $\mathrm{T}_{\mathrm{G}}$ ) in each organ scaled by the mass of administered chemical. Figure 3, Figure 4 and Figure 5 contains the information for free triclosan, triclosan glucuronide and triclosan sulfate respectively for human organs. Due to relatively high volume and low flow rate, the muscles and the fats contain high number of free triclosan and conjugates. As their plots are not compatible with the plots of remaining organs, a separate is used to show the level of chemicals in them. The difference in the level triclosan and its conjugates in the human blood after the oral and dermal exposure are shown in Figure 7. 

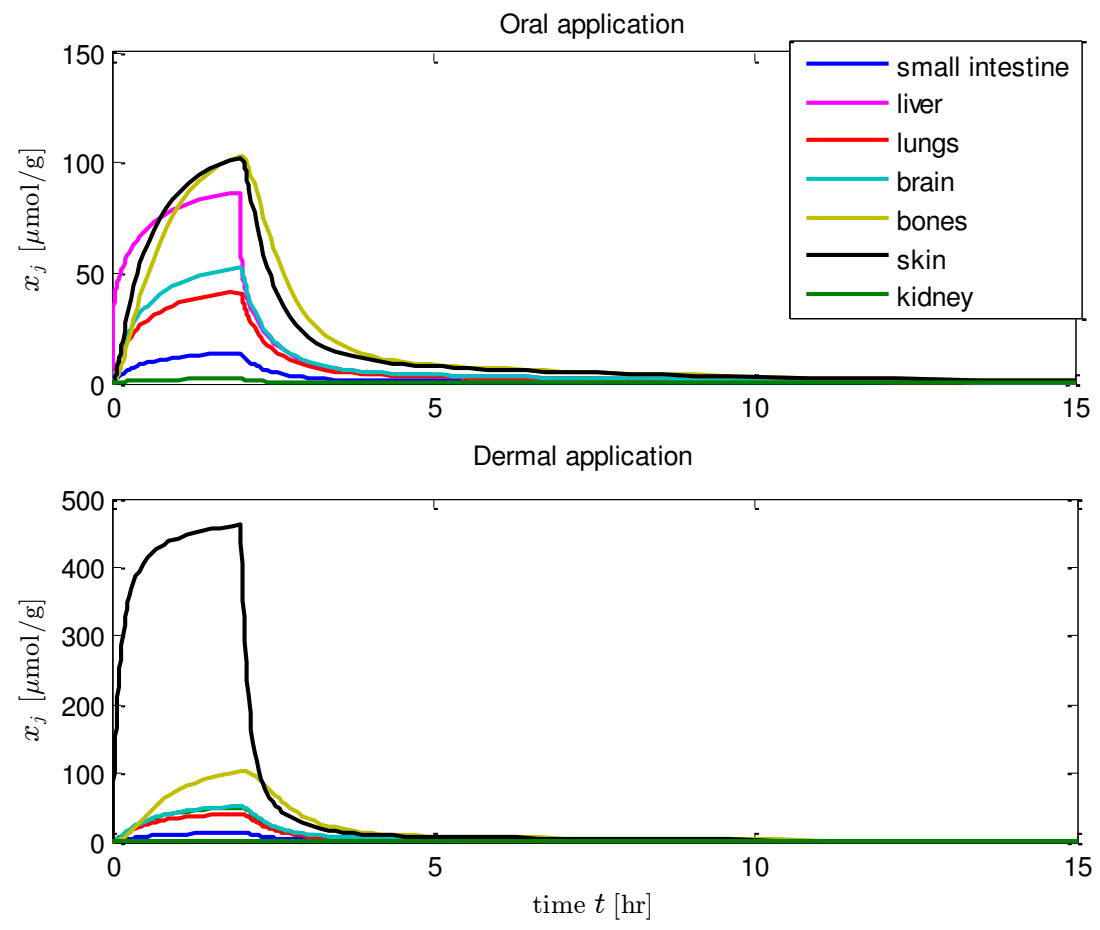

Figure 3: All accumulated molar mass of free triclosan scaled by total mass of administered chemical in human.
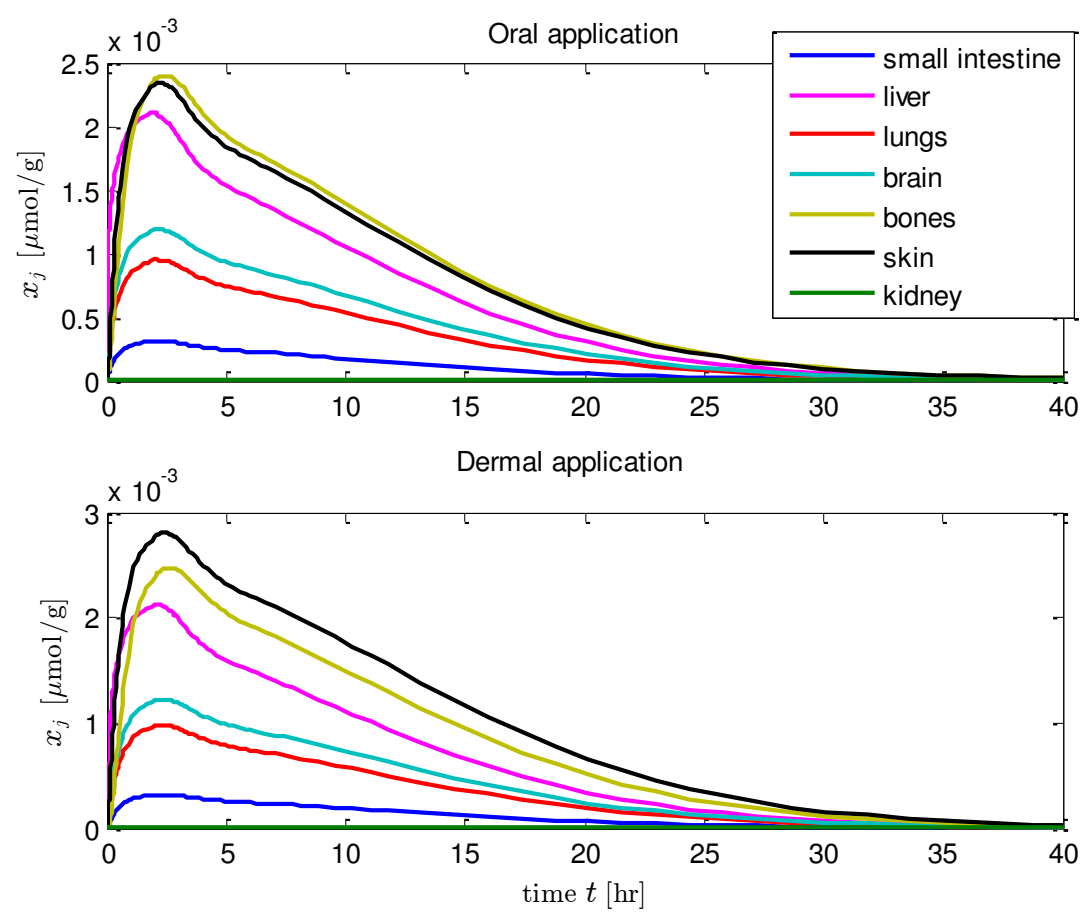

Figure 4: All accumulated molar mass of triclosan glucuronide scaled by total mass of administered chemical in human. 

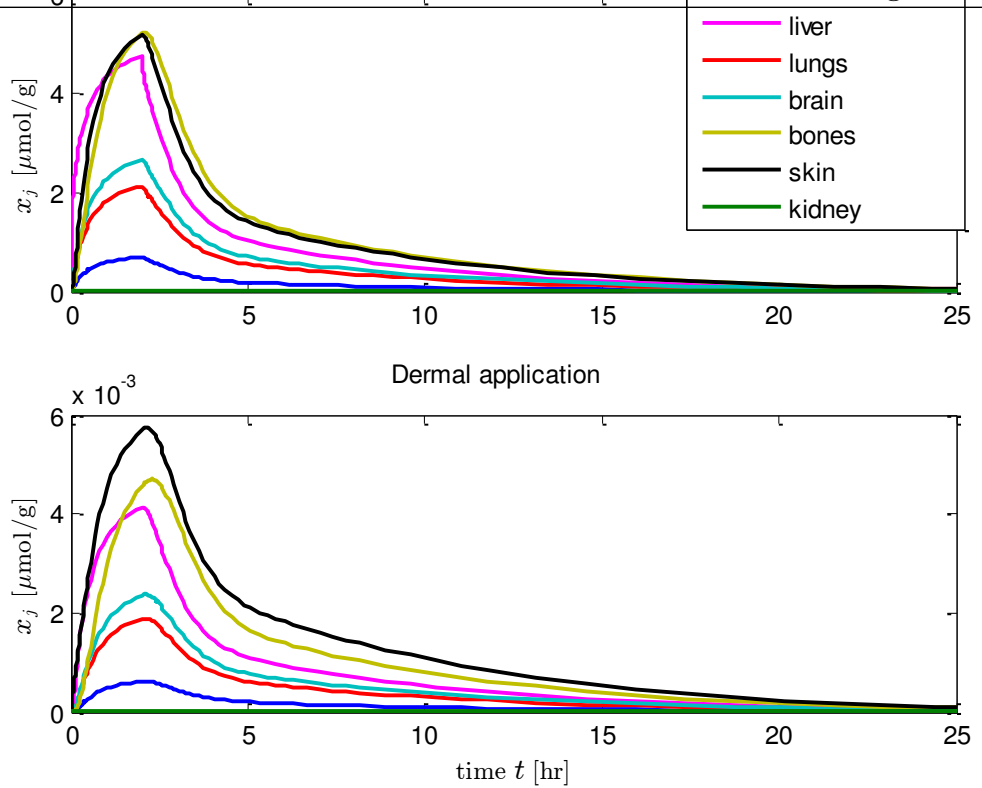

Figure 5: All accumulated molar mass of triclosan sulfate scaled by total mass of administered chemical in human.

Fats
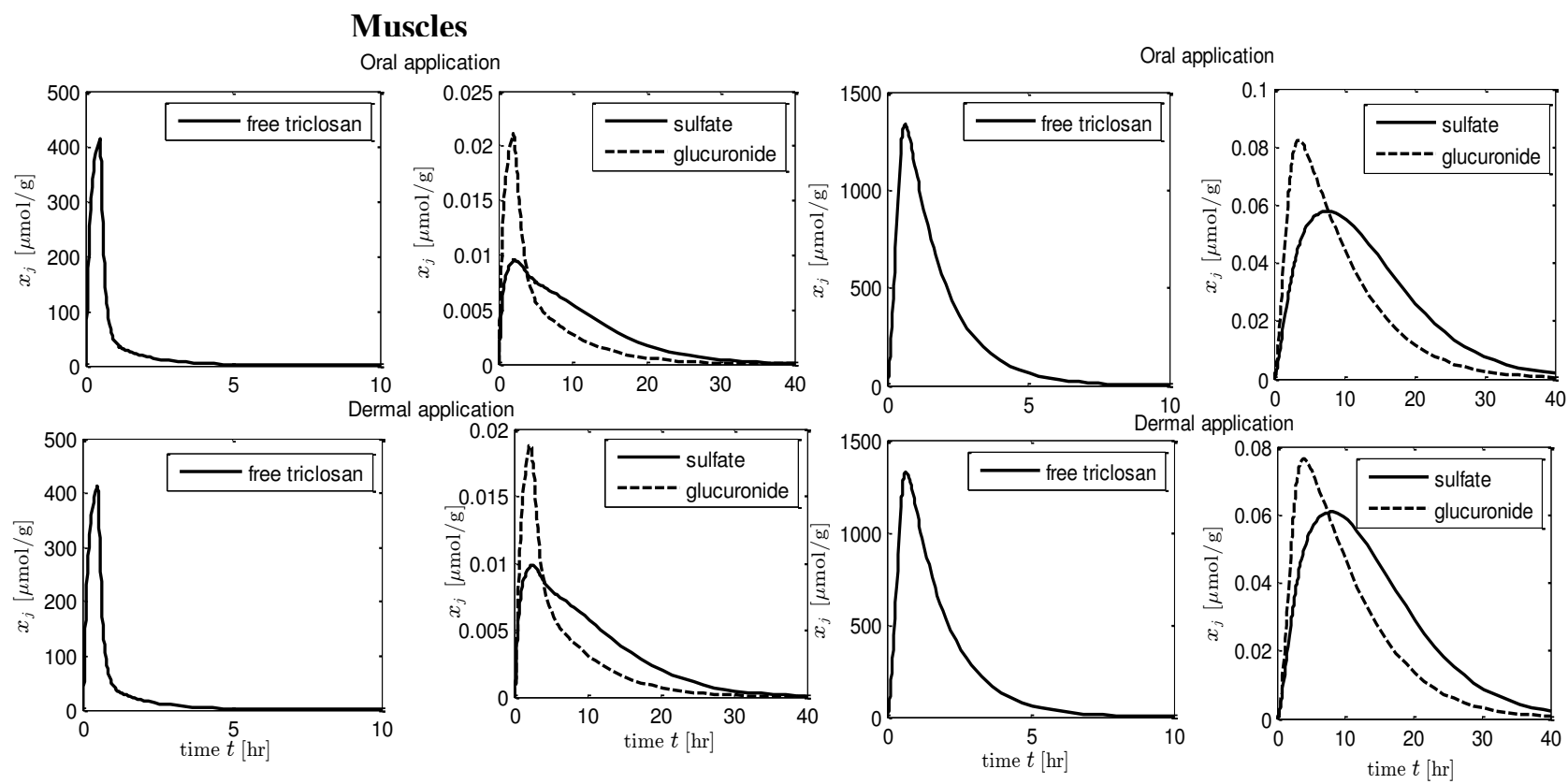

Figure 6: All accumulated molar mass scaled by total mass of administered chemicals in the muscles and the fats.

\section{Parameter Estimation}

\subsection{Sensitivity analysis}

Morris method is used for the sensitivity analysis of uncertain parameters. Here the concentration of free triclosan and its two conjugates in the liver are the chosen output for the analysis. The sensitivity analysis is performed by calculating the elementary effect (EE) for each uncertain parameter. The sensitivity measure using Morris method is only qualitified not quantitified (how much a given factor is more important than
others).Let the parameters be Pi where $\mathrm{i}=\{1 \ldots . .9\}$ for 9 uncertain parameters and output as the function of these parameters as $\mathrm{f}(\mathrm{Pi})$.Then elementary effect for first parameter, can be calculated as,

$$
E E_{1}^{j}=\frac{f\left(P_{1}^{j}+\Delta, P_{2}^{j} \ldots . . P_{9}^{j}\right)-f\left(P_{1}^{j}, P_{2}^{j} \ldots . P_{9}^{j}\right)}{\Delta} .
$$

Here $\mathrm{j}=\{1,2 \ldots \ldots \mathrm{k}\}$ if ' $\mathrm{k}$ ' number of random values for first parameter are considered within its upper and lower bound. So for 100 random values, there will be 100 EEs for the first parameter which will be later normalized. 

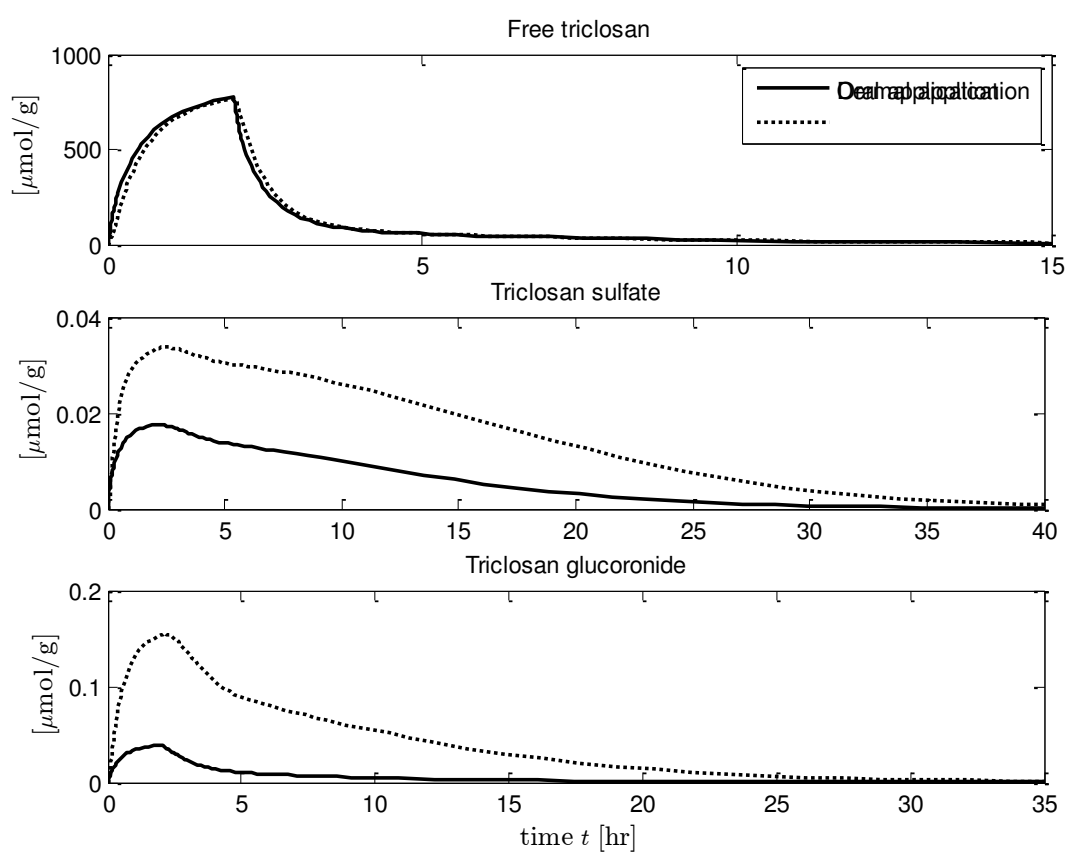

Figure 7: All accumulated molar mass scaled by total mass of administered chemicals in the human blood for the oral and dermal application.

If standard deviation is relatively small, the effect of that particular parameter on the output is "mildly nonlinear". If the standard deviation is relatively large, then the effect of the parameter on the output is "strongly non linear" (Ekstrom, 2005). Overall large measure of the mean of the EEs indicates a parameter with an important (overall) influence on the output. A high measure of the standard deviation of EEs may indicate that a parameter is highly interacting with other parameters. It may also indicate that the effect of this parameter is non linear (Morris, 1991).

Figure 8 shows the standard deviation of all uncertain parameters.

\subsection{Model fitting}

For least square method which is a widely used way to fit parameters, with following procedures: take differences between predicted values of y and observed values of $y$, square them and add up all the quantities for each of the data points. With data points (xi, yi), the predicted value of $y$ is $\mathrm{g}(\mathrm{xi} ; \mathrm{a})$, and the sum of squares is

$$
L(\mathbf{a})=\sum_{i=1}^{N}\left(y_{i}-g\left(x_{i} ; \mathbf{a}\right)\right)^{2}
$$

Obviously, the sum of squares depends on the parameter vector a, so we write $\mathrm{L}$ as a function of $\mathrm{a}$.

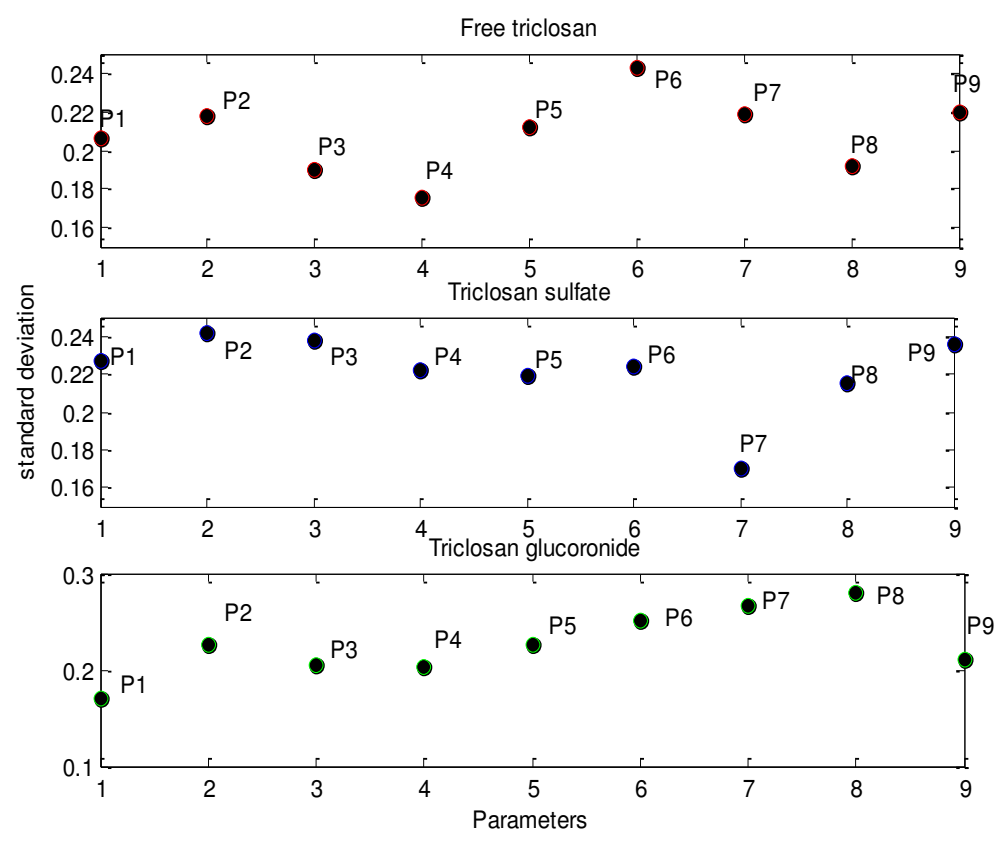

Figure 8: Standard deviation of EE for all uncertain parameters

$\mathrm{P}_{1}-\hat{\mathrm{r}}_{\text {max,G,li }} \mathrm{P}_{2}-\mathrm{K}_{\mathrm{T}, \mathrm{G}, \mathrm{li}} \mathrm{P}_{3}-\hat{\mathrm{r}}_{\max , \mathrm{S}, \mathrm{li}} \mathrm{P}_{4}-\mathrm{K}_{\mathrm{T}, \mathrm{S}, \mathrm{li}} \mathrm{P}_{5}-\hat{\mathrm{r}}_{\text {max,G,sk }}$ $\mathrm{P}_{6}-\mathrm{K}_{\mathrm{T}, \mathrm{G}, \mathrm{sk}} \mathrm{P}_{7}-\hat{\mathrm{r}}_{\text {max,S,sk }} \mathrm{P}_{8}-\mathrm{K}_{\mathrm{T}, \mathrm{S}, \mathrm{sk}} \mathrm{P}_{9}-\theta_{\mathrm{k} 2 \mathrm{u}}$ 
The task is to find the minimum of $\mathrm{L}$ (a) over different values of a. In general, this is not straightforward, unless the function $\mathrm{g}$ is linear.

Due to the lack of experimental data, synthetic data from the simulation with all parameter are sampled every hour and placed as predicted output. According to the sensitivity analysis, parameter P5 have almost same standard deviation in all three outputs whereas P7 and P8 show high standard deviation so these three parameters are taken for the model fitting. Assuming that these parameters are unknown ones, the model is glucuronide drops down faster than triclosan sulfate so after few hours the concentration of triclosan sulfate is higher. The pattern is same for almost all the organs. There is difference in the concentration level for the oral and the dermal route. In most of the organs, the concentration of free triclosan is relatively low whereas those of conjugates are relatively higher for the dermal application than oral application. The skin contains extremely high number of moles of free triclosan than other organs if the route of application is dermal. The Michaelis-Menten reaction parameters for triclosan
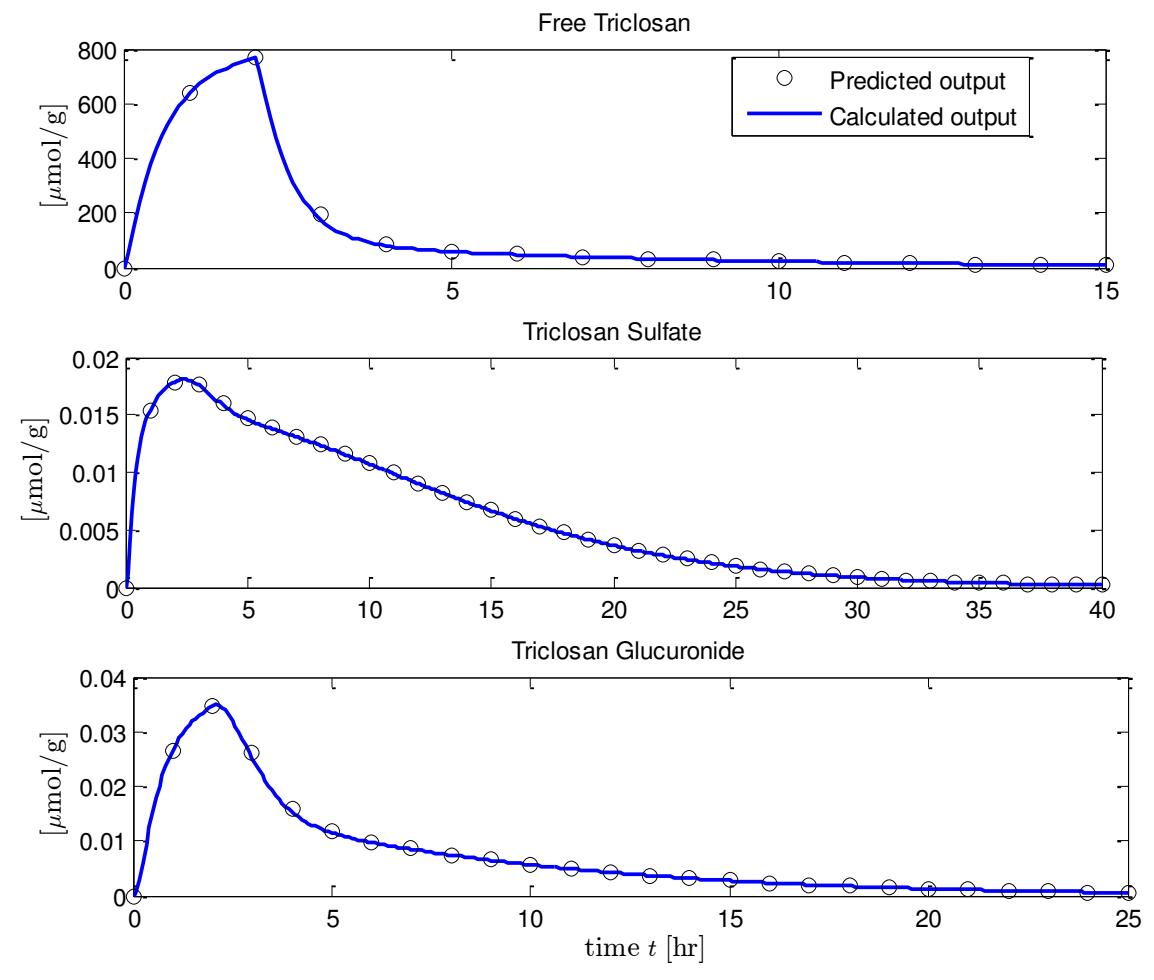

Figure 9: Synthetic measurements vs. model fitted output in the blood.

fitted with curve of synthetic data. The analysis is done for the concentration of free triclosan and its two conjugates in the blood as it will be easier to get sampling data from the blood. First simulation is done without adding any external noise to the predicted output (Figure 9) whereas second simulation is done with the addition of random noise into the predicted output (Figure 10). The random noises are generated between 0 to approximately $5 \%$ of peak value of calculated output when there was no noise.

\section{Results and Discussion}

The concentration of free triclosan seems to be very high during first few hours of exposure, but is rapidly distributed and excreted. The organ concentration of triclosan glucuronide was higher than that of triclosan sulfate. After exposure, the concentration of triclosan metabolism in human skin shows higher standard deviation that means small deviation in these parameters can affect the model drastically. This might be due to the fact that the sensitivity analysis is done for dermal application in which free triclosan is firstly metabolized in the skin.

Simulations show that within 15 hours of application $90 \%$ of the administered chemicals are metabolized into its conjugates. For no noise or very little noise in the sampled output model fitting works fine for 3 unknown parameters but there was some deviation from predicted output when noise is increased. So we cannot be sure about using model fitting for those models where there is possibility of high noise. 

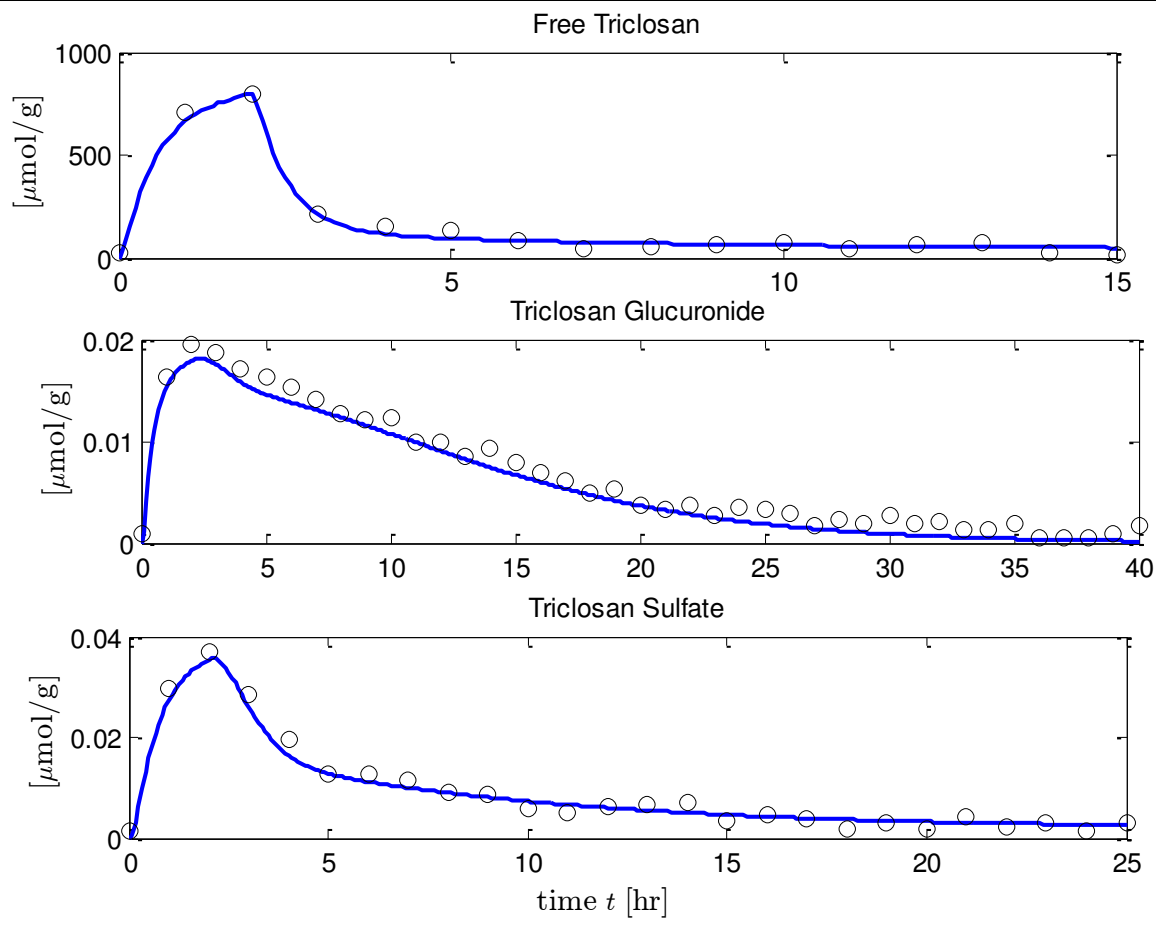

\section{Figure 10: Synthetic measurements with addition of random noise vs. model fitted} output in the blood

\section{Conclusion}

In this study, we demonstrate the concentration level of triclosan and its conjugates in the human organs with PBPK modeling. Large organs like muscles and fats contain relatively high concentration than other remaining organs. Due to the unavaibitlity of verified and experimental data the validation of developed model was not possible to be done.

\section{References}

Barter, ZE, Bayliss, MK, Beaune, PH, Boobis, AR, Carlile, DJ, \& Reisfeld, Brad. (2007). "Scaling Factors for the Extrapolation of In Vivo Metabolic Drug Clearance From In Vitro Data: Reaching a Consensus on Values of Human Microsomal Protein and Hepatocellularity Per Gram of Liver". Current Drug Metabolism, 8, 3345.

Beard, Daniel A. (2012). Biosimulation Simulation of Living Systems. Cambridge United Kingdom: Cambridge University Press.

Cubitt, Helen E., Houston, J. Brian, \& Galetin, Aleksandra. (2009). "Prediction of Human Drug Clearance by Multiple Metabolic Pathways: Integration of Hepatic and Intestinal Microsomal and Cytosolic Data". Drug Metabolism and Disposition, 39, 864-873.

Ekstrom, Per-Anders. (2005). "Eikos: A Simulation Toolbox for Sensitivity Analysis in MATLAB". FACILIA AB.
Fang, JL, Stingley, RL, Beland, FA, Harrouk, W, Lumpkins, DL, \& Howard, P. (2010). "Occurrence, efficacy, metabolism, and toxicity of triclosan". Journal of Environmental Science and Health, 28(3), 147-171.

Johnson, Trevor N., Tucker, Geoffrey T., Tanner, M. Stuart, \& Rostami-Hodjegan, Amin. (2005). "Changes in Liver Volume from Birth to Adulthood: A Meta-Analysis". Liver Transplantation, 12(11), 1481-1493.

Mielke, Hans, Abraham, Klaus, Gotz, Mario, Vieth, Barbel, Lampen, Alfonso, Luch, Andreas, \& Gundert-Remy, Ursula. (2011). "Physiologically based toxicokinetic modelling as a tool to assess target organ toxicity in route-to-route extrapolation- The case of courmarin". Toxicology Letters, 202, 100-110.

Mielke, Hans, \& Gundert-Remy, Ursula. (2012). "Physiologically Based Toxicokinetic Modelling as a Tool to Support Risk Assessment :Three Case Studies". Journal of Toxicology, 2012, 11.

Morris, Max D. (1991). "Factorial Sampling Plans for Preliminary Computational Experiments". Technometrics, 33, 161-174.

Moss, T, Howes, D, \& Williams, F. M. (2000). "Percutaneous Penetration and Dermal Metabolism of Triclosan (2,4,4'-Trichloro-2'hydroxydiphenyl Ether)". Food and Chemical Toxicology, 30, 360-370.

Rodricks, Joseph V, Swenberg, James A, Borzelleca, Joseph F, Maronpot, Robert R, \& Shipp, Annette M. (2010). "Triclosan: A critical review of the experimental data and development of margins of 
safety for consumer products". Critical Reviews in Toxicology, 40, 422-484.

Wang, Li-Quan, Falany, Charles N., \& James,

Margaret O. (2004). "Triclosan as a substrate and inhibitor of 3'-phosphoadenosine 5'phosphosulfate-sulfotransferase and udpglucuronosyl transferase in human liver fractions". Drug Metabolism and Disposition, 32, 1162-1169. 